\title{
Visualisation and Communication of VGI Quality
}

\author{
Andriani Skopeliti ${ }^{\star}$, Vyron Antoniou ${ }^{\dagger}$ and \\ Temenoujka Bandrova ${ }^{\ddagger}$
}

*School of Rural and Surveying Engineering, National Technical University of Athens, 9 H. Polytechniou, Zografou, 15780, Greece, askop@survey.ntua.gr ${ }^{\dagger}$ Hellenic Army General Staff, Geographic Directorate, PAPAGOU Camp,

Mesogeion 227-231, Cholargos, 15561, Greece

*University of Architecture, Civil Engineering and Geodesy, 1, Chr.

Smirnenski blvd., Sofia, Bulgaria

\begin{abstract}
The flourishing of VGI projects has transformed the average web user into an eager geographic data user and contributor. As it is difficult for the crowd to perceive VGI quality, visualisation can play a critical role in communicating data quality. At the same time, although VGI quality has been a prominent research topic for scientists, quality visualisation has not been exploited to its full potential. Since the crowd encompasses a diverse pool of users, VGI quality visualisation caters for different needs and exhibits variable functionality, operating as an awareness tool for the novice user as well as an exploration tool for the expert user / scientist. The scope of this chapter is to present a framework for VGI quality visualisation that takes into account factors such as methods for quality visualisation of spatial data, the nature of VGI data quality, user profiles and the visualisation environment. In addition, a review of the available methods for data quality visualisation, which have emerged from cartography,
\end{abstract}

How to cite this book chapter:

Skopeliti, A, Antoniou, V and Bandrova, T. 2017. Visualisation and Communication of VGI Quality. In: Foody, G, See, L, Fritz, S, Mooney, P, Olteanu-Raimond, A-M, Fonte, C C and Antoniou, V. (eds.) Mapping and the Citizen Sensor. Pp. 197-222. London: Ubiquity Press. DOI: https://doi.org/10.5334/bbf.i. License: CC-BY 4.0 
is presented, and a number of guidelines for VGI quality visualisation are proposed, taking into account user characteristics.

\section{Keywords}

quality, VGI, visualisation, VGI quality awareness, VGI quality exploration, visualisation framework

\section{Introduction}

Quality visualisation of geospatial data is as important as the data themselves (Pang, 2001). The recent development in VGI projects, such as OpenStreetMap (OSM) and Geonames, makes this topic even more critical and challenging, as novice users now access, use and create geographic information. The novice user does not question the quality of VGI data, as he/she is either unaware of the quality issue or erroneously believes that quality problems do not exist in the dataset. The source of geographic data (i.e. VGI vs. proprietary/authoritative) is not perceived as an important factor when determining the credibility of a map (Parker, 2014). A nicely designed map in terms of cartography and an operational map environment, e.g. OSM, is considered as a reliable source. Judgement is based on peripheral signals such as visual design and symbology (e.g. 'if it looks good and attractive, then it is good'; Idris et al., 2011). Quality reporting in text and tables may be easily understood by experts but not by the diverse pool of VGI users. Since visualisation can communicate data quality to all users (Buttenfield, 1983; Drecki, 2002; MacEachren et al., 2005), it is proposed to use visualisation to reveal VGI data quality.

VGI quality has been given particular attention by scientists. Much of the work concentrates on assessing and reporting VGI quality in diverse outlets, but only a few studies include visualisations. According to the OSM wiki, there are a number of online web pages characterised as 'Visualisation tools' to 'Quality assurance. However, these mainly refer to error and bug reporting tools with maps and do not constitute an actual quality visualisation environment. Visualisation has not been exploited to its full potential and scientists have not taken full advantage of its capabilities. As a result, researchers miss aspects of VGI quality that visualisation could reveal. One may assume that in the early days of VGI, VGI quality measures and indicators were not mature enough to be visually represented: past research has suggested that without a good understanding of quality, effective approaches to visualisation remain elusive (MacEachren et al., 2005). However, a review of the literature indicates the existence of a plethora of measures and indicators that now manage to successfully express VGI quality (see e.g. Antoniou and Skopeliti, 2015; Senaratne et al., 2016). 


\subsection{The Role of VGI Quality Visualisation}

Visualisation can be used to communicate VGI quality to the crowd (Figure 1). Visualisation transforms VGI quality from an issue that is rather ignored and difficult to perceive into a perceptible and vivid data characteristic. As the crowd consists of a diverse pool of users in terms of knowledge and experience with spatial data, VGI quality visualisation needs to satisfy different requirements. Visualisation is applicable to two distinct but related activities: visual thinking, which is exploratory and engages scientists; and visual communication, which is explanatory and refers to the distribution of existing knowledge (DiBiase et al., 1992). Thus VGI quality visualisation can have multiple functionalities: it can be considered as an awareness tool for the novice user as well as an exploration tool for the expert user / scientist. Users with intermediate knowledge and experience can take advantage of the different functionalities depending on their abilities. In more detail, VGI data quality visualisation can be considered:

- An awareness tool for the novice user that can be used to draw the attention of the crowd to VGI quality; force the crowd to question VGI quality; communicate quality in a way that can be understood by the layperson; stimulate contribution improvements; etc. Many research projects (MacEachren et al., 1995; Leitner and Buttenfield, 2000; Cliburn et al., 2002; Deitrick, 2007) have demonstrated that quality visualisation supports the process of

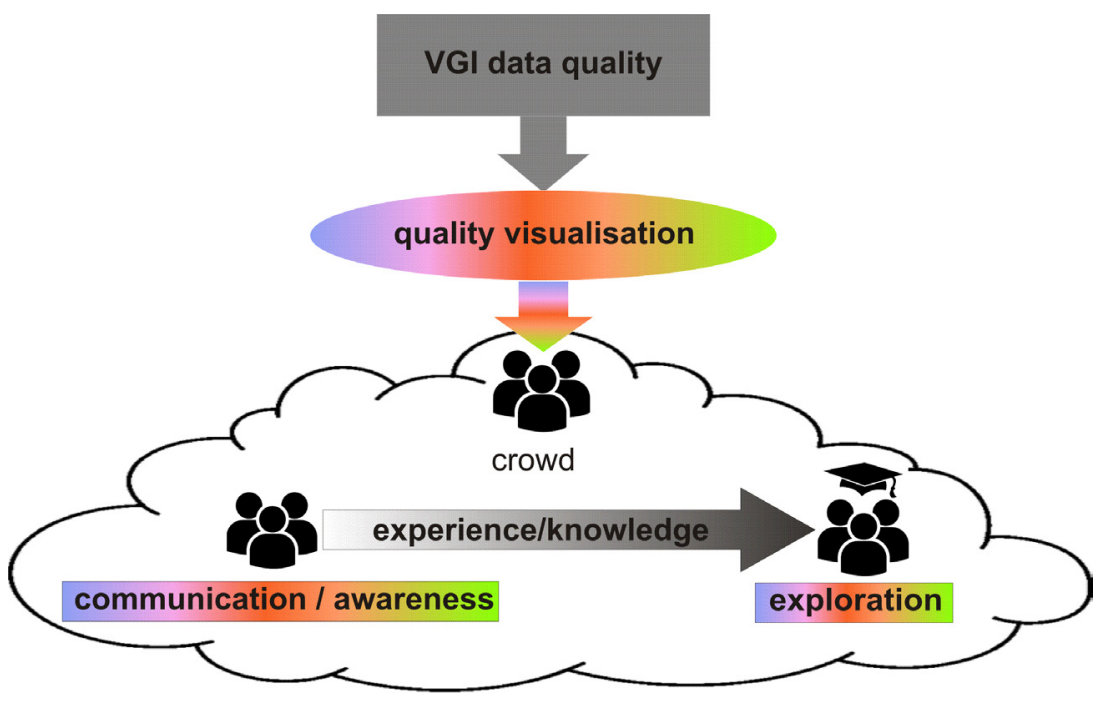

Fig. 1: VGI data quality, visualisation, users and functionality. 
decision-making and leads to significantly better decisions. Consequently, it is important to inform users about data quality in order to select VGI data that are appropriate for a specific purpose. Although experts do not find uncertainty visualisation overwhelming, confusing or useless (Kunz, 2011), with so many non-expert VGI users, there is a need to make sure that visualisation is understandable by all users, not only expert ones (Jones, 2011). This can be achieved by exploring the full potential of data quality visualisation and selecting the appropriate methods.

- And an exploration tool for the expert user / scientist that can aid researchers to study the appropriateness and the ability of measures and indicators to express quality; to discover dependencies to extrinsic socio-economic or demographic factors; to explore the spatial distribution and heterogeneity of VGI quality; etc.

\subsection{A Framework for VGI Quality Visualisation}

In the previous paragraph, the role of VGI quality visualisation as an awareness and as an exploration tool has been discussed. However, although VGI quality visualisation is acknowledged as necessary, it is also considered as a big challenge (Sester et al., 2014). As a result, a framework for VGI quality visualisation that can facilitate and guide the successful design of VGI quality visualisation is much welcomed; this framework acknowledges four interactive parameters that influence VGI quality visualisation (Figure 2):

i) VGI Data Quality: The framework takes into account the nature of VGI datasets, the applicable data quality elements and the measures and indicators used to measure quality - see Chapter 7 by Fonte et al. (2017) and Chapter 13 by Olteanu-Raimond et al. (2017a).

ii) Quality Visualisation Methods: Well established methods for spatial data quality visualisation that emerge from the domain of cartography can be integrated in the framework. Accumulated cartographic knowledge can provide a number of best practices for a successful visual communication and exploration of quality (see Section 4).

iii) Users: The framework caters for end users of all backgrounds. The members of the diverse pool of VGI users, who range from novice users to scientists, are the final recipients of data quality, and their needs should be covered through effective visualisation processes.

iv) Medium/Visualisation Environment: The framework exploits the opportunities of the medium used to deliver the map (i.e. computer or mobile devices) and the availability of a number of smart tools such as a graphical user interface (GUI), interactive controls, etc. that create a rich and effective visualisation environment. 


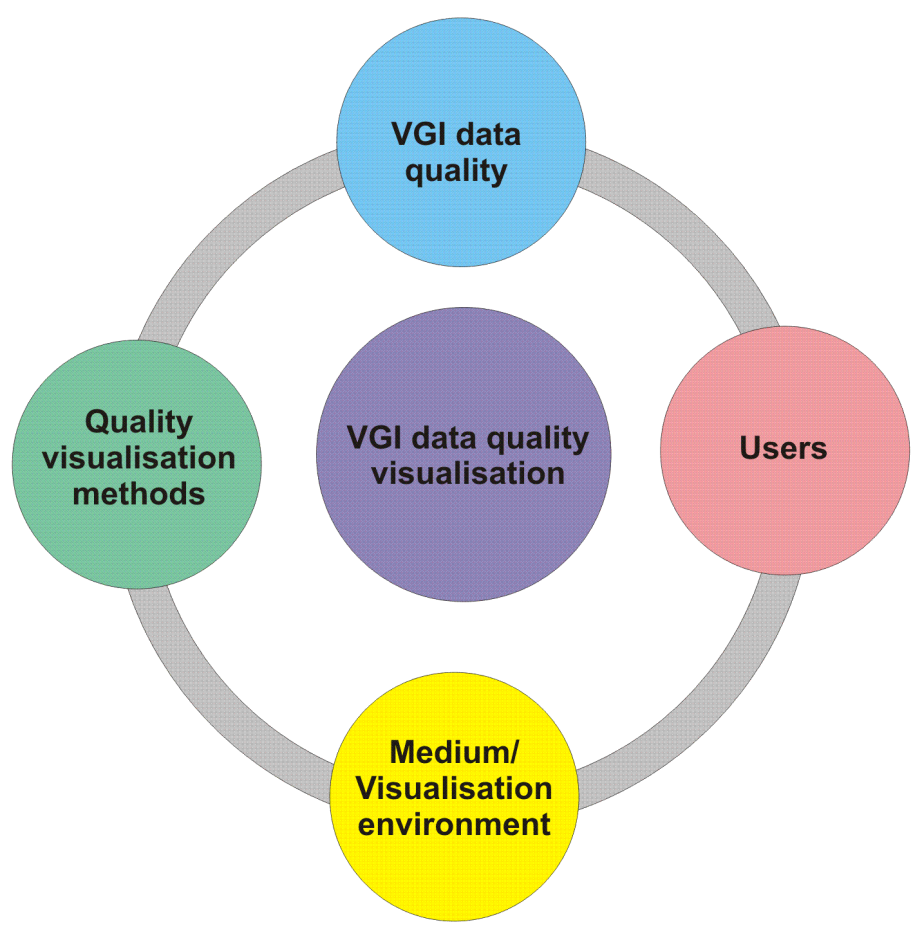

Fig. 2: A framework for VGI quality visualisation.

The above factors of the VGI quality visualisation framework are discussed in detail in Section 3.

In this context, the paper is structured as follows: Section 2 provides an overview of the present status of VGI quality visualisation, Section 3 describes in detail the elements of the framework for VGI quality visualisation and Section 4 presents the state of the art in data quality visualisation methods, providing specific guidelines for VGI data quality visualisation. The chapter ends with conclusions and proposals for future work.

\section{Present Status of VGI Quality Visualisation}

\subsection{Measures and Indicators for VGI Quality}

Scientists assess VGI quality with measures and indicators (see Chapter 7 by Fonte et al., 2017). A number of studies have tried to estimate VGI quality by comparing VGI with proprietary data (e.g. Girres and Touya, 2010; Haklay, 
2010; Zielstra and Zipf, 2010), utilising measures that emerge from quality assessment, data matching, generalisation evaluation, etc. Because measures are not sufficient for characterising VGI quality, academic research focuses on data quality indicators. Indicators can be categorised into (Antoniou and Skopeliti, 2015): i) data indicators (see e.g. Barron et al., 2014; Ciepłuch et al., 2010a; Keßler and de Groot, 2013; van Exel et al., 2010); ii) demographic indicators (see e.g. Haklay, 2010; Haklay et al., 2010; Mullen et al., 2015; Tulloch, 2008; Zielstra and Zipf, 2010); iii) socio-economic indicators (see e.g. Antoniou, 2011; Elwood et al., 2013; Girres and Touya, 2010; Haklay et al., 2010); and iv) contributor indicators (see e.g. D’Antonio et al., 2014; Nedović-Budić and Budhathoki, 2010). Since VGI quality is currently assessed with a plethora of measures and indicators, the need for visual representation makes VGI quality visualisation highly topical.

\subsection{VGI Quality Visualisation}

Once meta-information about VGI quality is available, there are different ways to portray it graphically. Only a few of the VGI quality studies have provided a visualisation of the quality; the next paragraphs present a detailed review of the visualisation methods applied in these studies.

\subsubsection{Measures}

A number of studies access VGI quality with measures based on the comparison of VGI and proprietary data and provide quality visualisation (e.g. Antoniou, 2011; Fan et al., 2014; Forghani and Delavar, 2014; Haklay, 2010). Values of quality measures (e.g. distance between features, length difference of the road network, the area and density difference of buildings, etc.) are calculated for a grid that covers the study area, and are portrayed utilising colour schemes based on hue and value.

\subsubsection{Contributor Indicators}

Other studies assess the 'perceived quality' instead of the 'measured quality', i.e. user perception about the data quality, which is based on personal opinion and commentary and feedback from other users, is portrayed. Inspired by the popular web rating system that is utilised in sites such as Amazon, eBay, iTunes, etc. and that assesses quality on a 1 to 5 rating system, the quality visualisation proposed by Jones (2011) results in a Virtual Globe with glyphs (e.g. star 2D, star $3 \mathrm{D}$ ), where visual variables such as size and colour portray the magnitude of quality. Schiewe (2013) records the opinion of the user for the current region 
of interest in OSM with a 'like' or 'dislike' button and visualises it with pictograms such as smiling faces, targets, etc.

\subsubsection{Data Indicators}

In recent studies, a number of data indicators have been proposed and visualised. Two different approaches are observed: indicators can be computed and visualised at the feature level or using grid cells that cover the study area. In the first approach, nodes, points and lines are used. For example, Trame and Keßler (2011) visualised the number of versions for OSM POIs (Points of Interest) by using a colour spectral scheme (heat $\mathrm{map}^{2}$ ) and overlaid the representation onto OSM. In another study (van Exel, 2011a), contour lines were used to visualise the average number of version (updates) of any node in the OSM database. Contours of different values were visualised with different hues. Van Exel (2011b) also proposed a combined visualisation of two metrics for the linear OSM features: (i) the time passed since a feature has last been updated by the community is visualised using a hue colour scheme and (ii) the number of versions, indicating how many updates a feature has received since its creation, is visualised using the width of the linear symbol. In another study (Keßler and de Groot, 2013), the trustworthiness of selected features was assessed by the numbers of versions, users, confirmations, corrections and rollbacks and was then visualised with different hue colour schemes. Two cases of interactive visualisation have also been recorded. Antoniou (2011) used an interactive map, which could alternate between data and quality visualisation, to visualise conceptual compliance to the OSM wiki-based specifications for each feature, using a hue colour scheme. In iOSMAnalyzer (Barron et al., 2013), 25 intrinsic measures referring to 'General Area Information', 'Routing \& Navigation', 'AddressSearch', 'Points of Interest-Search', 'Map-Applications' and 'User-Information \& -Behavior' were calculated and portrayed in maps using hue colour schemes.

Other studies in the literature take the second approach, which is the gridbased approach. The densities of points and other indicators (Ciepłuch et al., 2010b) for OSM data have been computed for a grid and visualised utilising a colour spectrum scheme. In Roick et al. (2012), OSM data for Europe were divided into hexagonal cells and a number of spatio-temporal quality metrics (user activity, topicality and number of features) were calculated and visualised with hue and value colour schemes in a web application. The conceptual compliance (Ballatore and Zipf, 2015) of tags was calculated on a $10 \mathrm{~km}^{2}$ grid and portrayed using a value colour scheme. In another study (Camboim et al., 2015), completeness (number of buildings $/ \mathrm{km}^{2}$, road density, road length, percentage of unclassified roads) and temporal quality (number of editors and days since last edition) were computed for administrative regions and visualised utilising a number of hue and value colour schemes. 


\subsection{Evaluation of Existing VGI Quality Visualisations}

From the above analysis, it becomes evident that VGI quality assessment has been conducted per feature or per area (grid cell or administrative area) and that this pattern is followed for VGI quality visualisation as well. The visualisation of VGI quality, as it appears in the studies mentioned above, can be characterised as cartographically poor. Although a number of methods for quality visualisation exist in the cartographic literature (see Section 4), only a few of them have been applied. Most cases use only colour schemes based on hue and value. Additionally, quality visualisation is notably presented separately, independently from the data, offline and asynchronously. Thus, it does not permit quality judgement while looking at the data, and it obscures data visualisation, as attribute information is lost. With poor symbolisation or design choices, quality visualisation leads to more, rather than less, uncertainty about the data depicted (MacEachren et al., 2005). Practices for VGI quality visualisation need to be revised and updated based on a framework for VGI quality visualisation.

\section{A Framework for VGI Quality Visualisation}

The scope of this section is to discuss in detail the components of the framework for VGI quality visualisation presented in Section 1. Each component is analysed in order to present its contribution to quality visualisation. Finally, a number of guidelines are proposed that can help the design of a VGI quality visualisation environment.

\subsection{VGI Data Quality}

The nature of VGI datasets - see Chapter 2 by See et al. (2017) and Chapter 3 by Mooney and Minghini (2017) - and their quality aspects play an important role in the choices regarding visualisation. Past research (Buttenfield and Beard, 1994; Buttenfield and Weibel, 1988; MacEachren, 1992; MacEachren, 1995) has proved that the selection of a visualisation method should be related to the quality element represented and the measure/indicator used. The main information that users need about VGI quality focuses on fitness-foruse. Since fitness-for-use depends on a number of quality elements (such as positional accuracy, completeness, currency, etc.) and on criteria related to the planned use of the data, users may need to be presented with visualisations for a number of data quality measures and indicators in order to reach a decision on the suitability of a dataset. As a result, in order for users to fully benefit from the provision of various measures and indicators, a wide variety 
of visualisation methods should be provided, enhanced with interactivity to maximise functionality.

The nature of the quality indicator or measure affects the functionality of the visualisation as an awareness tool or as an exploratory tool. For instance, quality measures that are computed through comparison with authoritative data, although descriptive, cannot be used to support the quality awareness role: they are computed offline, post-processing is needed and they depend on the existence of reference data, which is not always the case. On the contrary, they are considered valuable for VGI quality exploration by scientists. Visualisation, as a VGI quality awareness tool, requires quality indicators that can only be calculated in real time from the VGI data or other available data, for simultaneous provision to the user.

Therefore, in order to provide for good understanding of quality and fitnessfor-use judgement, one should provide a number of data quality measures and indicators along with visualisation support. Specific visualisation functionality, e.g. quality awareness or quality exploration, is made possible by selecting the appropriate quality descriptors, as explained above.

\subsection{Quality Visualisation Methods}

Quality visualisation can be handled as the cartographic portrayal of any other spatial phenomenon. Thus, the analysis of the measure/indicator and the values that describe it, of the classification according to geometry (point, line, area), and of the measurement scale (continuous or discrete; ordinal or categorical) will lead to the selection of the appropriate visualisation method. VGI data visualisation and quality visualisation should work together as a whole (holistic/symbiotic approach) and balance simplicity, detail, richness of visualisation and ease of understanding. Technical feasibility should also be considered. Methods should not be too complex, so that they can be applied easily within the framework of a VGI project.

One of the most attractive developments in cartography, which are based on modern technologies, is $3 \mathrm{D}$ mapping. 3D maps pose new challenges to cartographers, as these representations must be very well adapted to the context of the user and must provide understandable and easy-to-perceive information and messages. Some VGI data can be mapped in 3D. The 'third dimension is a growing topic in OSM (OpenStreetMap Wiki, 2017), for example, a number of web pages provide maps with $3 \mathrm{D}$ rendering of buildings. Data quality visualisation methods are considered to be adaptable to the 3D context, yet the subject hides big challenges (Bandrova et al., 2012; Jones, 2011; Pang et al., 1997).

A detailed review of available quality visualisation techniques emerging from cartography, as well as guidelines to select the appropriate methods taking into account usability and user experience, is presented in Section 4. 


\subsection{Users}

An important factor for successful map design is to know who the audience is. Regarding VGI, there will always be a group of unknown users despite the effort of producers to register volunteers and involve them in user groups (Vullings et al., 2015). Since cartographic representations can only be optimised if end users and data types are known (Kunz et al., 2011), it is impossible to provide successful VGI quality visualisations for all users. Users with no knowledge of visualisation quality will work with a map differently than a professional who has been dealing with the issue for some time (Brus and Pechanec, 2015). Fortunately, the dual role of visualisation as a communication and as an exploration tool (DiBiase et al., 1992) can serve all VGI user needs. The idea of levels of uncertainty visualisation in relation to the experience and needs of the user is discussed in Beard and Mackaness (1993). Three levels are distinguished: the first level is simply a notification of poor data quality, with 'poor' defined on the basis of a predetermined threshold; the second level adds detail, such as the location and type of quality conflict, etc.; and the third level focuses on giving users methods for investigating the reasons for uncertainty. A VGI quality visualisation environment should provide for all users and take into account different user needs and characteristics. Based on this context, VGI quality visualisation design should address the profiles of at least two user groups, which are opposites in terms of experience and knowledge: the novice user profile and the expert user / scientist profile.

\subsection{Medium/Visualisation Environment}

Among the quality visualisation methods addressed in the literature, a frequently repeated idea is that users need control over depictions of quality (MacEachren et al., 2005). Cliburn et al. (2002) proposed to help users cope with the complexity of the display by providing interactivity. Interactive functionality can facilitate the interpretation of visualisation and cater for the different needs of heterogeneous user groups. A number of choices can be available in interactive functionality: selection among different cartographic methods for the visualisation (see Section 4); or customisation of the selected visualisation method according to user needs, e.g. configuration of visual variables such as colour schemes based on hue and value, symbol sizes, and data quality value classification, among others. Once the visualisation meets the requirements of the user (Kunz et al., 2011), the cartographic representation can be analysed visually, or, in addition, explored with the help of further functionality (e.g. a tooltip window displaying detailed information). Of course only expert users can make good use of strong interactivity, whereas novice users may be restricted to graphic modification of visualisations. 
Graphical user interfaces (GUIs) are a powerful tool in visualisation support as they enhance functionality, through e.g. the graphic modification of visualisations, screen division and simultaneous display of data and quality visualisation in neighbouring windows, interactive tools such as a 'quality slider' that controls the appearance of the data in relation to quality, buttons that control whether different components - data or quality - should be visually dominant, etc. Functionality classification, based on Cron et al. (2007), includes: general functions, functions for navigation, didactic functions, cartographic and visualisation functions and GIS functions. Cartographic and visualisation functionality (Cron et al., 2007) refers to map manipulation, redlining (addition of drawings, labelling, and comments) and exploratory data analysis.

Apart from the need for the ability of a visualisation method to be understandable by any user, another important factor is the technical feasibility of the visualisation method's implementation (Jones, 2011). Technological advances can now provide geospatial applications with interactivity, flexibility and user friendliness so as to create the perfect environment for VGI quality visualisation. The integration of these qualities in the GUIs of a VGI project (irrespective of the device used) will further enhance the effort to communicate quality.

As a result, the design of the visualisation environment should strike a balance between interactivity, cartographic and visualisation functionality, and technical feasibility, taking into account the expected functionality, e.g. quality awareness or quality exploration, and the user profile, e.g. novice user or expert user/scientist.

\subsection{Guidelines for VGI Quality Visualisation Implementation}

From the above analysis of the framework, a number of guidelines may arise that can help the design of VGI quality visualisation:

- Various data quality measures and indicators should be provided to the user in order to achieve successful communication of quality and permit a successful fitness-for-use judgement;

- The nature of the VGI pool of users should be addressed and user needs and characteristics taken into account; in particular, user profiles on the opposite ends of the experience and knowledge spectrum (the novice user and the expert user / scientist) should be taken into account;

- Visualisation functionality e.g. quality awareness or quality exploration should be provided by selecting the appropriate quality descriptors or measures;

- Visualisation techniques and guidelines emerging from cartography that take usability and user profile into account should be applied; and

- A visualisation environment that balances interactivity with cartographic and visualisation functionality and technical feasibility should be designed. 


\section{A Review of Methods for Quality Visualisation}

Research in the field of quality visualisation for geospatial data has been ongoing for the last 30 years (Aerts et al., 2003; Buttenfield and Beard, 1994; Buttenfield and Weibel, 1988; Drecki, 2002; Goodchild et al., 1994; Leitner and Buttenfield, 2000; MacEachren, 1992; MacEachren et al., 2005; McGranaghan, 1993; Van der Wel et al., 1998; Wittenbrink et al., 1996; Zuk and Carpendale, 2006). In this section, papers about geographic data uncertainty and quality visualisation are reviewed and summarised, in order to acquire a catalogue of methods/techniques that can be applied to VGI quality visualisation. This review may act as an informative guide for designing a VGI quality visualisation.

The main challenge of any visualisation effort is to select the most appropriate method. Symbolisation is based on visual variables introduced by Bertin (1983). These include location; size; shape; orientation; colour hue; colour value (or brightness (Wilkinson, 2005), or lightness (Slocum et al., 2003)); texture (grain); colour saturation; arrangement (Morrison, 1974); clarity (fuzziness); resolution (of boundaries and images); and transparency (MacEachren, 1992). MacEachren (1995) describes the syntax for the above visual variables, giving a three-step rating of good, marginal and poor, for use with numerical, ordinal and categorical data (Roth, 2015).

In this paper, visualisation methods are presented in tables according to the classification that appears in the bibliography (Gershon, 1998; Kinkeldey et al., 2014a; MacEachren et al., 2005). First, intrinsic visualisation methods are presented in Table 1. Intrinsic visualisation methods (Howard and MacEachren, 1996) alter the symbology used to portray data values to additionally represent quality, through manipulation of a visual variable that has not been used to portray data values, e.g. the colour value. Table 1 presents the visual variables that can be used to portray quality. In order to make the functionality of visual variables understandable to non-experts, the notion of a visualisation metaphor was introduced by MacEachren (1992), was adopted by other researchers (e.g. Kardos et al., 2006) and is also integrated in Table 1. A number of the visual variables presented in Table 1 can be used in combination with hue (Hengl, 2003; Howard and MacEachren, 1996), resulting in combinations such as hue, saturation and value or value and hue, in order to form colour schemes, e.g. sequential colour schemes, diverging colour schemes, and qualitative colour schemes (Brewer, 1994; Harrower and Brewer, 2003). Such schemes can be applied in bivariate representations, which depict data and quality together, treating quality as a second variable (Kunz et al., 2011; MacEachren et al., 2005). All intrinsic approaches have in common the fact that slight changes in uncertainty can be difficult to identify, especially for datasets with great variability (Kunz et al., 2011). However, this can be mitigated with the help of interactive functionality. 


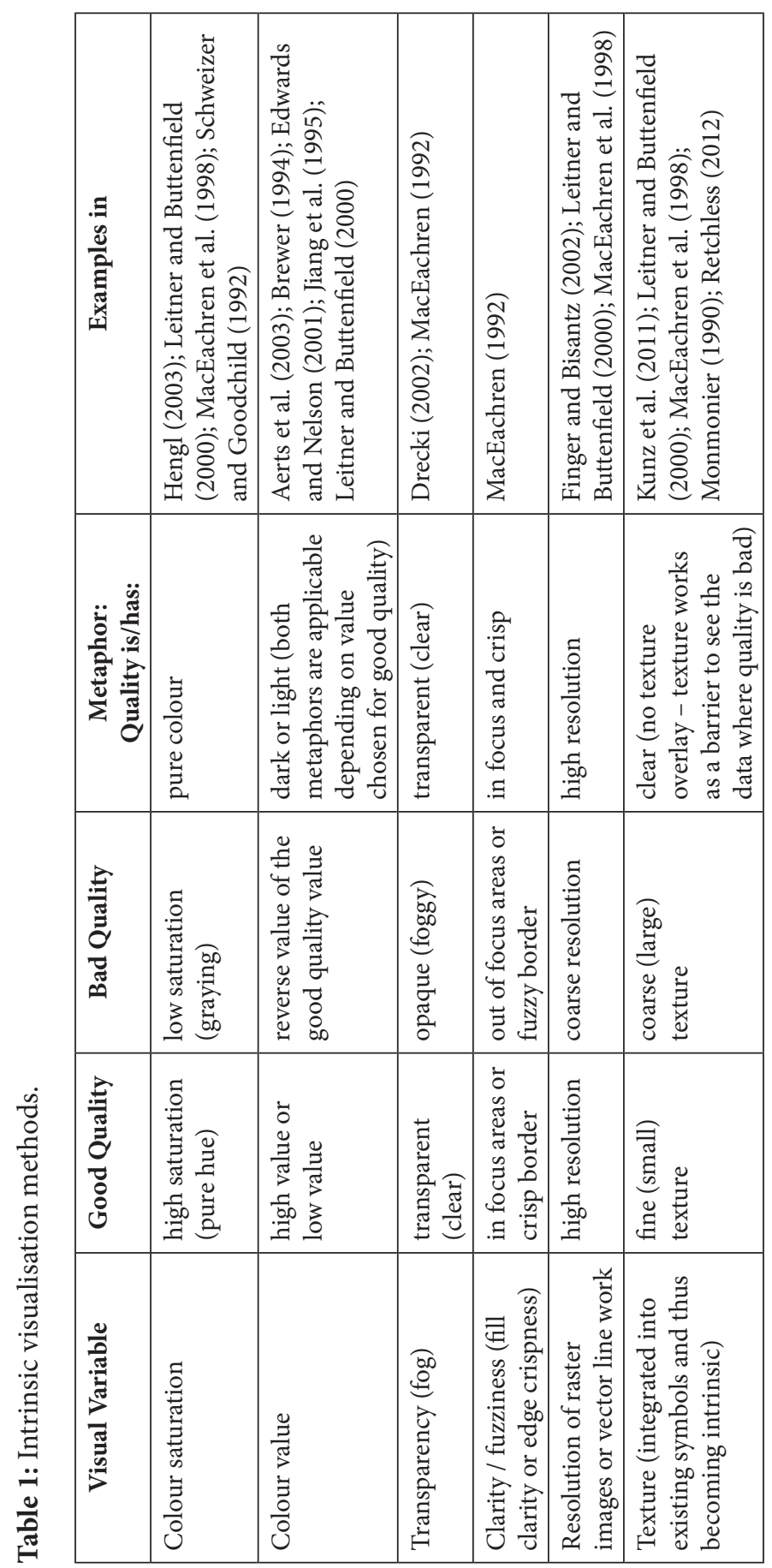


Table 2: Extrinsic visualisation methods.

\begin{tabular}{|l|l|l|l|}
\hline Method & \multicolumn{1}{|c|}{ Description } & $\begin{array}{l}\text { Visual variable to } \\
\text { portray quality }\end{array}$ & \multicolumn{1}{|c|}{ Examples in } \\
\hline Glyphs & $\begin{array}{l}\text { graphical objects with } \\
\text { 2D or 3D geometry, } \\
\text { such as circle, sphere, } \\
\text { vertical bar, pyramid, } \\
\text { square etc. }\end{array}$ & $\begin{array}{l}\text { size, colour value, } \\
\text { saturation etc. }\end{array}$ & $\begin{array}{l}\text { McKenzie et al. (2016); } \\
\text { Pang (2001); Slocum et } \\
\text { al. (2003) }\end{array}$ \\
\hline Contours & $\begin{array}{l}\text { lines that represent } \\
\text { same values (isolines) } \\
\text { of quality }\end{array}$ & $\begin{array}{l}\text { size (thickness), } \\
\text { colour value } \\
\text { (brightness), } \\
\text { connectedness, } \\
\text { colour hue, } \\
\text { texture etc. }\end{array}$ & $\begin{array}{l}\text { DiBiase et al. } \\
\text { (1992); Howard and } \\
\text { MacEachren (1996); } \\
\text { Pang (2008) }\end{array}$ \\
\hline $\begin{array}{l}\text { Grids / } \\
\text { Tessellations }\end{array}$ & $\begin{array}{l}\text { a grid or other } \\
\text { tessellation e.g. } \\
\text { hexagons overlaid to } \\
\text { the data }\end{array}$ & $\begin{array}{l}\text { size (grid } \\
\text { size), texture } \\
\text { (grid pattern), } \\
\text { grid outline } \\
\text { (boundaries) etc. }\end{array}$ & $\begin{array}{l}\text { Cedilnik and Rheingans } \\
\text { (2000); Kardos et al. } \\
\text { (2008); Kinkeldey et al. } \\
\text { (2014b); Mullins (2014); } \\
\text { Pang (2008) }\end{array}$ \\
\hline
\end{tabular}

Extrinsic techniques (Howard and MacEachren, 1996), which introduce new objects to depict quality, e.g. glyphs, grids, etc., that work independently of the existing symbols for data values, are presented in Table 2. These new objects portray quality using appropriate visual variables such as size, colour value, texture, etc.

In terms of visual organisation, extrinsic visualisation methods (Gershon, 1998; Howard and MacEachren, 1996) can be coincident, if data and quality are represented in one map, or adjacent, if they are represented in adjacent maps. (Intrinsic visualisations are, by definition, coincident.)

Finally, quality visualisation methods can be static, like the ones already presented, or dynamic. Dynamic representations are presented in Table 3. Animation is related to three basic design elements, or 'dynamic variables': scene duration, rate of change between scenes and scene order (DiBiase et al., 1992). The range of possible dynamic approaches is wide because elements from animation and interaction can be combined in numerous ways. Intrinsic and extrinsic visualisation methods are static, but they can also be transformed into dynamic methods through animation.

\subsection{Quality Visualisation Methods and VGI Data}

A number of studies that present methods for quality visualisation have also studied their usability (Aerts et al., 2003; Cliburn et al., 2002; Fisher, 1993; 
Table 3: Dynamic visualisation methods.

\begin{tabular}{|c|c|c|c|}
\hline $\begin{array}{l}\text { Dynamic } \\
\text { Variable }\end{array}$ & $\begin{array}{l}\text { Quality is } \\
\text { represented by }\end{array}$ & Metaphor & Examples in \\
\hline Sound & sonic variables & $\begin{array}{l}\text { a low pitch sound depicts } \\
\text { good quality and a high pitch } \\
\text { sound, bad quality. It can be } \\
\text { cursor-driven. }\end{array}$ & $\begin{array}{l}\text { Fisher (1994) 1994; } \\
\text { Krygier (1994); } \\
\text { Lodha et al. (1996) }\end{array}$ \\
\hline \multirow[t]{4}{*}{ Animation } & scene duration & $\begin{array}{l}\text { long duration of an object } \\
\text { on the screen depicts good } \\
\text { quality }\end{array}$ & $\begin{array}{l}\text { Fisher (1993); } \\
\text { MacEachren et al. } \\
(1998)\end{array}$ \\
\hline & $\begin{array}{l}\text { rate of change } \\
\text { between scenes }\end{array}$ & $\begin{array}{l}\text { questionable quality is } \\
\text { portrayed with rapid } \\
\text { blinking }\end{array}$ & $\begin{array}{l}\text { Evans (1997); Fisher } \\
\text { (1993); Monmonier } \\
\text { and Gluck (1994); } \\
\text { Kardos et al. (2006) }\end{array}$ \\
\hline & $\begin{array}{l}\text { spatially variable } \\
\text { blurring }\end{array}$ & $\begin{array}{l}\text { questionable quality is } \\
\text { portrayed with very blurred } \\
\text { regions }\end{array}$ & $\begin{array}{l}\text { Gershon (1992); } \\
\text { MacEachren et al. } \\
(2005)\end{array}$ \\
\hline & scene order & $\begin{array}{l}\text { multiple representations: } \\
\text { a number of possible data } \\
\text { values are represented, } \\
\text { and the existence of many } \\
\text { different values creates } \\
\text { questions on quality }\end{array}$ & $\begin{array}{l}\text { Bastin et al. (2002); } \\
\text { Ehlschlaeger et al. } \\
\text { (1997) }\end{array}$ \\
\hline
\end{tabular}

Gershon, 1992; Kardos et al., 2006; Kinkeldey et al., 2014a; Lodha et al., 1996; MacEachren et al., 1998; Pang, 2001; Schweizer and Goodchild, 1992). In the following paragraphs, a number of guidelines for VGI quality visualisation in relation to user experience are discussed, once again taking the two main user profiles into account: the novice user and the expert user/scientist.

Which method to use (intrinsic vs. extrinsic): Slocum et al. (2003) found that intrinsic techniques give a better overview of uncertainty, but that in-depth analysis is easier with extrinsic techniques. This is in agreement with Kunz et al. (2011), who noted that none of the intrinsic approaches can successfully portray the variability in quality. As a result, it is proposed to use intrinsic methods as awareness tools for novice users and extrinsic methods as exploratory tools for the experts.

Which visual variable to use in intrinsic visualisations: Regarding the intuitiveness needed for novice users (MacEachren et al., 2012), colour value, fog (transparency) and clarity (fuzziness) visual metaphors are preferable. On the other hand, expert users prefer transparency or saturation (Kunz, 2011). In terms of user performance, Kinkeldey et al. (2014a) conclude that colour saturation is not recommended, while colour hue and value as well as transparency 
provide better alternatives. Also, texture on colour fill and resolution lead to good results and thus can be used with intrinsic visualisations.

Which variable to use in extrinsic methods: Studies on extrinsic displays (Kinkeldey et al., 2014a) highlight the potential of glyph and grid-based techniques for quality representation. According to a different usability study (Senaratne et al., 2012), contours are considered the best method.

Which technique (coincident vs. adjacent) to use: Research suggests that both coincident and adjacent approaches have their applications. According to Kinkeldey et al. (2014a), coincident maps can be seen as the preferable option because the integration of uncertainty into the display makes it easier to retrieve data and quality simultaneously. This is why they are advised for the novice users in order to ensure that quality information will not escape their attention. The problem of advanced complexity, which may be an obstacle for the novice user, can be minimised with good cartographic design and interactivity (e.g. use of on/off buttons). Expert users can work with both techniques and should be able to decide which one to use.

Static or dynamic: There is evidence (Kinkeldey et al., 2014a) that animated views have a potential to successfully represent quality when static solutions are not feasible, but there is little evidence that they perform equally or better than more traditional static depictions when these are available. Regarding dynamic techniques, animations are the most promising ones as they can be used to attract the attention of the user (Gershon, 1992; Blenkinsop et al., 2000). Thus, dynamic visualisations can be used with novice users in order to highlight VGI quality issues and increase awareness. Expert users can again work with all of the methods, and they should be able to decide which one to use.

Scale: Finally, one should consider the dynamic scale of the VGI display environment, e.g. the OSM web page. The scale plays an important role in the selection of an appropriate visualisation method, as intrinsic methods are best for larger scales and extrinsic methods such as grid and contours are preferable for a global quality visualisation at smaller scales.

\section{Conclusions and Future Plans}

From the above analysis, it is clear that there is an emerging need for VGI data quality visualisation. A number of measures and indicators for VGI quality (Antoniou and Skopeliti, 2015) have been proposed, there is knowledge on quality visualisation (MacEachren et al., 2005; Kinkeldey et al., 2014a) and the technology is now available. Since the crowd encompasses a diverse pool of users, VGI quality visualisation should cater for different needs and exhibit variable functionality, operating as an awareness tool for the novice user as well as an exploration tool for expert users / scientists. A framework for successful VGI quality visualisation was presented, incorporating factors such as the 
nature of VGI data quality, user profiles, methods for quality visualisation of spatial data, and the visualisation environment.

Effective VGI quality visualisation will have a positive impact on a VGI project's overall quality: quality visualisation will help users decide on fitness-foruse, the quality of contributions will improve, the reputation of VGI will rise as quality is better communicated through visualisation, quality awareness will increase, sceptical users will change their opinion (since most of the time VGI quality is better than expected) and quality metadata hidden in data will be revealed, e.g. by utilising information from history files or elapsing tags in the case of OSM. Thus there are only merits to VGI quality visualisation for both VGI data and VGI projects.

VGI quality visualisation is also of interest to National Mapping and Cadastral Agencies (NMCAs) that embrace VGI. Today many NMCAs encourage and welcome VGI contributions in their geoportals (see Chapter 13 by Olteanu-Raimond et al., 2017a). Volunteers are playing an increasingly important role in ensuring that authoritative sources of geographic information are accurate and kept up-to-date. VGI data and authoritative data can be visualised in the geoportal of NMCAs and one of the aforementioned methods can be employed to portray quality. Data will be enhanced, but at the same time the user will be informed about data quality. Whereas authoritative data can be better in terms of quality elements such as homogeneity (Olteanu-Raimond et al., 2017b), VGI may prove to be better in terms of completeness (Vandecasteele and Devillers, 2015), currency (Goodchild and Glennon, 2010) and positional accuracy (Haklay, 2010). These differences in quality may only become apparent, especially to non-experts, through visualisation.

For the future development of this research topic, it is proposed to create a prototype for VGI quality visualisation, combining existing measures and indicators (Antoniou and Skopeliti, 2015) of VGI quality with a variety of visualisation methods (MacEachren et al., 2005; Kinkeldey et al., 2014a). For the choice of suitable visualisation methods for the crowd, it is important to confirm the usability and effectiveness of methods with the pool of VGI users. The prototype can be used to conduct a user survey that records and evaluates the crowd response on VGI quality visualisation and verifies methods in practice. Knowledge about VGI quality visualisation as it relates specifically to the crowd acquired through a user survey can then be implemented in the development of an interactive visualisation environment in the framework of any VGI project.

\section{Notes}

${ }^{1}$ http://wiki.openstreetmap.org/wiki/Quality_assurance\#Visualisation_tools

2 A heat map utilizes a colour scheme that is part of the colour spectrum; it is called heat map because this colour scheme is traditionally used in cartography for the visualisation of temperature. 


\section{Reference list}

Aerts, J.C.J.H., Clarke, K.C., Keuper, A.D., 2003. Testing popular visualization techniques for representing model uncertainty. Cartography and Geographic Information Science 30, 249-261. DOI: https://doi. org/10.1559/152304003100011180

Antoniou, V., 2011. User Generated Spatial Content: An Analysis of the Phenomenon and its Challenges for Mapping Agencies. Unpublished $\mathrm{PhD}$ Thesis. University College London (UCL), London, UK.

Antoniou, V., Skopeliti, A., 2015. Measures and indicators of VGI quality: An overview, in: ISPRS Annals of the Photogrammetry, Remote Sensing and Spatial Information Sciences. Presented at the ISPRS Geospatial Week 2015, ISPRS Annals, La Grande Motte, France, pp. 345-351.

Ballatore, A., Zipf, A., 2015. A conceptual quality framework for Volunteered Geographic Information, in: Fabrikant, S.I., Raubal, M., Bertolotto, M., Davies, C., Freundschuh, S., Bell, S. (Eds.), Spatial Information Theory. Springer International Publishing, Cham, pp. 89-107.

Bandrova, T., Zlatanova, S., Konecny, M., 2012. Three-dimensional maps for disaster management. ISPRS Annals of Photogrammetry, Remote Sensing and Spatial Information Sciences I-4, 245-250. DOI: https://doi.org/10.5194/ isprsannals-I-4-245-2012

Barron, C., Neis, P., Zipf, A., 2014. A comprehensive framework for intrinsic OpenStreetMap quality analysis. Transactions in GIS 18, 877-895. DOI: https://doi.org/10.1111/tgis.12073

Barron, C., Neis, P., Zipf, A., 2013. iOSMAnalyzer - ein umfassendes Werkzeug für intrinsische OSM Qualitätsuntersuchungen, in: Proceedings of the AGIT 2013 - Symposium und Fachmesse Angewandte Geoinformatik, Wichmann, Salzburg, 3-5 July, Austria, pp. 142-151.

Bastin, L., Fisher, P.F., Wood, J., 2002. Visualizing uncertainty in multi-spectral remotely sensed imagery. Computers \& Geosciences 28, 337-350. DOI: https://doi.org/10.1016/S0098-3004(01)00051-6

Beard, K., Mackaness, W., 1993. Visual access to data quality in Geographic Information Systems. Cartographica: The International Journal for Geographic Information and Geovisualization 30, 37-45. DOI: https://doi. org/10.3138/C205-5885-23M7-0664

Bertin, J., 1983. Semiology of graphics: Diagrams, networks, maps (Translation from a French 1967 edition by W.Berg, editor). University of Wisconsin Press, Madison, WI, USA.

Blenkinsop, S., Fisher, P., Bastin, L., Wood, J., 2000. Evaluating the perception of uncertainty in alternative visualization strategies. Cartographica: The International Journal for Geographic Information and Geovisualization 37, 1-14. DOI: https://doi.org/10.3138/3645-4V22-0M23-3T52

Brewer, C.A., 1994. Color use guidelines for mapping and visualization, in: MacEachren, A.M., Taylor, D.R.F. (Eds.), Visualization in Modern Cartography. Elsevier Science Limited, Tarrytown, NY, USA, pp. 123-148. 
Brus, J., Pechanec, V., 2015. The user centered framework for visualization of spatial data quality, in: Brus, J., Vondrakova, A., Vozenilek, V. (Eds.), Modern Trends in Cartography. Springer International Publishing, Cham, pp. 325-338.

Buttenfield, B.P., 1983. Representing data quality. Cartographica 30, 1-7.

Buttenfield, B.P., Beard, M.K., 1994. Graphical and geographical components of data quality, in: Unwin, D.J., Hearnshaw, H. (Eds.), Visualization in Geographic Information Systems. John Wiley \& Sons, London, UK, pp. 150-157.

Buttenfield, B.P., Weibel, R., 1988. Visualizing the quality of cartographic data, in: Proceedings of the Third International Geographic Information Systems Symposium (GIS/LIS 88), San Antonio, Texas, USA, 30 November - 2 December.

Camboim, S.P., Bravo, J.V.M., Sluter, C.R., 2015. An investigation into the completeness of, and the updates to, OpenStreetMap data in a heterogeneous area in Brazil. ISPRS International Journal of Geo-Information 4, 1366-1388. DOI: https://doi.org/10.3390/ijgi4031366

Cedilnik, A., Rheingans, P., 2000. Procedural annotation of uncertain information, in: Visualization 2000. Proceedings. Presented at the Visualization 2000. Proceedings, pp. 77-84. DOI: https://doi.org/10.1109/VISUAL.2000.885679

Ciepłuch, B., Jacob, R., Mooney, P., Winstanley, A., 2010a. Comparison of the accuracy of OpenStreetMap for Ireland with Google Maps and Bing Maps, in: Proceedings of the Ninth International Symposium on Spatial Accuracy Assessment in Natural Resources and Environmental Sciences, University of Leicester, UK, 20-23 July, pp. 37-40. Available at: http://eprints. maynoothuniversity.ie/2476/1/Accuracy2010-Ciepluch-Submitted.pdf

Ciepłuch, B., Jacob, R., Winstanley, A., Mooney, P., 2010. Comparison of the accuracy of OpenStreetMap for Ireland with Google Maps and Bing Maps, in: Proceedings of the Accuracy 2010 Symposium, Leicester, UK, 20-23 July. Available at: http://www.spatial-accuracy.org/system/files/imgX07133419_0.pdf

Cliburn, D.C., Feddema, J.J., Miller, J.R., Slocum, T.A., 2002. Design and evaluation of a decision support system in a water balance application. Computers \& Graphics 26, 931-949. DOI: https://doi.org/10.1016/S00978493(02)00181-4

Cron, J., Sieber, R., Hurni, L., 2007. Guidelines to optimized graphical user interfaces of interactive atlases, in: Proceedings of the 23rd International Cartographic Conference, Moscow, Russia, 4-10 August. Available at: http:// icaci.org/files/documents/ICC_proceedings/ICC2007/documents/doc/ THEME\%2015/Oral\%205/GUIDELINES\%20TO\%20OPTIMIZED\%20 GRAPHICAL\%20USER\%20INTERFACES\%20OF\%20INTERAC.doc [Last accessed 16 May 2017].

D’Antonio, F., Fogliaroni, P., Kauppinen, T., 2014. VGI edit history reveals data trustworthiness and user reputation, in: Proceedings of 17th AGILE International Conference on Geographic Information Science, Castellón, Spain, 
3-16 June. Available at: https://agile-online.org/conference_paper/cds/ agile_2014/agile2014_140.pdf [Last accessed 16 May 2017].

Deitrick, S.A., 2007. Uncertainty visualization and decision making: Does visualizing uncertain information change decisions?, in: Proceedings of the XXIII International Cartographic Conference. Presented at the XXIII International Cartographic Conference, pp. 4-10.

DiBiase, D., MacEachren, A.M., Krygier, J.B., Reeves, C., 1992. Animation and the role of map design in scientific visualization. Cartography and Geographic Information Science 19, 201-214. DOI: https://doi. org/10.1559/152304092783721295

Drecki, I., 2002. Visualisation of uncertainty in geographical data, in: Shi, W., Fisher, P., Goodchild, M. (Eds.), Spatial Data Quality. Taylor \& Francis, London, UK, pp. 140-159, NaN-143.

Edwards, L.D., Nelson, E.S., 2001. Visualizing data certainty: A case study using graduated circle maps. Cartographic Perspectives 38, 19-36.

Ehlschlaeger, C.R., Shortridge, A.M., Goodchild, M.F., 1997. Exploratory Cartograpic VisualisationVisualizing spatial data uncertainty using animation. Computers \& Geosciences 23, 387-395. DOI: https://doi.org/10.1016/ S0098-3004(97)00005-8

Elwood, S., Goodchild, M.F., Sui, D., 2013. Prospects for VGI research and the emerging fourth paradigm, in: Sui, D., Elwood, S., Goodchild, M. (Eds.), Crowdsourcing Geographic Knowledge. Springer Netherlands, Dordrecht, pp. 361-375.

Evans, B.J., 1997. Dynamic display of spatial data-reliability: Does it benefit the map user? Computers \& Geosciences 23, 409-422. DOI: https://doi. org/10.1016/S0098-3004(97)00011-3

Fan, H., Zipf, A., Fu, Q., Neis, P., 2014. Quality assessment for building footprints data on OpenStreetMap. International Journal of Geographical Information Science 28, 700-719. DOI: https://doi.org/10.1080/13658816.2013. 867495

Finger, R., Bisantz, A.M., 2002. Utilizing graphical formats to convey uncertainty in a decision-making task. Theoretical Issues in Ergonomics Science 3, 1-25. DOI: https://doi.org/10.1080/14639220110110324

Fisher, P.F., 1994. Randomization and sound for the visualization of uncertain spatial information, in: Unwin, D.J., Hearnshaw, H. (Eds.), Visualization in Geographic Information Systems. John Wiley \& Sons, London, UK, pp. 181-185.

Fisher, P.F., 1993. Visualizing uncertainty in soil maps by animation. Cartographica: The International Journal for Geographic Information and Geovisualization 30, 20-27. DOI: https://doi.org/10.3138/B204-32P4-263L-76W0

Fonte, C C, Antoniou, V, Bastin, L, Estima, J, Arsanjani, J J, Bayas, J-C L, See, L and Vatseva, R. 2017. Assessing VGI Data Quality. In: Foody, G, See, L, Fritz, S, Mooney, P, Olteanu-Raimond, A-M, Fonte, C C and Antoniou, V. 
(eds.) Mapping and the Citizen Sensor. Pp. 137-163. London: Ubiquity Press. DOI: https://doi.org/10.5334/bbf.g.

Forghani, M., Delavar, M., 2014. A quality study of the OpenStreetMap dataset for Tehran. ISPRS International Journal of Geo-Information 3, 750-763. DOI: https://doi.org/10.3390/ijgi3020750

Gershon, N.D., 1998. Visualization of an imperfect world. IEEE Computer Graphics and Applications 18, 43-45. DOI: https://doi.org/10.1109/38.689662

Gershon, N.D., 1992. Visualization of fuzzy data using generalized animation. Visualization, 1992. Visualization '92, Proceedings, IEEE Conference on, Boston, MA, pp. 268-273. DOI: https://doi.org/10.1109/VISUAL.1992.235199

Girres, J.-F., Touya, G., 2010. Quality assessment of the French OpenStreetMap dataset. Transactions in GIS 14, 435-459.

Goodchild, M.F., Chih-Chang, L., Leung, Y., 1994. Visualizing fuzzy maps, in: Unwin, D.J., Hearnshaw, H. (Eds.), Visualization in Geographic Information Systems. John Wiley \& Sons, London, UK, pp. 158-167.

Goodchild, M.F., Glennon, J.A., 2010. Crowdsourcing geographic information for disaster response: a research frontier. International Journal of Digital Earth 3, 231-241. DOI: https://doi.org/10.1080/17538941003759255

Haklay, M., 2010. How good is volunteered geographical information? A comparative study of OpenStreetMap and Ordnance Survey datasets. Environment and Planning B: Planning and Design 37, 682-703. DOI: https://doi. org/10.1068/b35097

Haklay, M., Basiouka, S., Antoniou, V., Ather, A., 2010. How many volunteers does it take to map an area well? The validity of Linus' Law to volunteered geographic information. The Cartographic Journal 47, 315-322.

Harrower, M., Brewer, C.A., 2003. ColorBrewer.org: An online tool for selecting colour schemes for maps. The Cartographic Journal 40, 27-37. DOI: https://doi.org/10.1179/000870403235002042

Hengl, T., 2003. Visualisation of uncertainty using the HIS colour model: Computations with colours, in: Proceedings of the 7 th International Conference on GeoComputation. Southampton, UK, p. 8-17.

Howard, D., MacEachren, A.M., 1996. Interface design for geographic visualization: Tools for representing reliability. Cartography and Geographic Information Science 23, 59-77. DOI: https://doi.org/10.1559/152304096782562109

Idris, N.H., Jackson, M.J., Abrahart, R.J., 2011. Colour coded traffic light labelling: An approach to assist users in judging data credibility in map mashup applications, in: Proceedings of the 7th International Symposium on Spatial Data Quality, Coimbra, Portugal, 12 - 14 October, p. 201-206.

Jiang, B., Ormeling, F., Kainz, W., 1995. Visualization support for fuzzy spatial analysis, in: Auto Carto 12. Charlotte, NC, USA, pp. 291-300.

Jones, K., 2011. Communicating perceived geospatial data quality of 3D objects in virtual globes. MSc Thesis. School of Graduate Studies, Department of Geography, Memorial University of Newfoundland. 
Kardos, J., Moore, A., Benwell, G., 2008. Exploring tessellation metaphors in the display of geographical uncertainty, in: Moore, A., Drecki, I. (Eds.), Geospatial Vision, Lecture Notes in Geoinformation and Cartography. Springer Berlin Heidelberg, pp. 113-140.

Kardos, J., Moore, A., Benwell, G., 2006. Expressing attribute uncertainty in spatial data using blinking regions, in: Caetano, M., Painho, M. (Eds.), Proceedings of the 7th International Symposium on Spatial Accuracy Assessment in Natural Resources and Environmental Sciences, Lisbon, Portugal, 5-7 July, pp. 814-824. Available at: http://www.spatial-accuracy.org/system/ files/Kardos2006accuracy.pdf [Last accessed 16 May 2017].

Keßler, C., de Groot, R.T.A., 2013. Trust as a proxy measure for the quality of Volunteered Geographic Information in the case of OpenStreetMap, in: Vandenbroucke, D., Bucher, B., Crompvoets, J. (Eds.), Geographic Information Science at the Heart of Europe. Springer International Publishing, Cham, pp. 21-37.

Kinkeldey, C., MacEachren, A.M., Schiewe, J., 2014a. How to assess visual communication of uncertainty? A systematic review of geospatial uncertainty visualisation user studies. The Cartographic Journal 51, 372-386. DOI: https://doi.org/10.1179/1743277414Y.0000000099

Kinkeldey, C., Mason, J., Klippel, A., Schiewe, J., 2014b. Evaluation of noise annotation lines: using noise to represent thematic uncertainty in maps. Cartography and Geographic Information Science 41, 430-439. DOI: https:// doi.org/10.1080/15230406.2014.949868

Krygier, J., 1994. Sound and geographic visualization, in: Unwin, D.J., Hearnshaw, H. (Eds.), Visualization in Geographic Information Systems. John Wiley \& Sons, London, UK, pp. 149-166.

Kunz, M.H., 2011. Interactive visualizations of natural hazards data and associated uncertainties. Doctoral dissertation, ETH, Zurich, Switzerland. Available at: http://e-collection.library.ethz.ch/eserv/eth:2927/eth-2927-01.pdf [Last accessed 16 May 2017].

Kunz, M.H., Grêt-Regamey, A., Hurni, L., 2011. Visualization of uncertainty in natural hazards assessments using an interactive cartographic information system. Natural Hazards 59, 1735-1751. DOI: https://doi.org/10.1007/ s11069-011-9864-y

Leitner, M., Buttenfield, B.P., 2000. Guidelines for the display of attribute certainty. Cartography and Geographic Information Science 27, 3-14. DOI: https://doi.org/10.1559/152304000783548037

Lodha, S.K., Pang, A., Sheehan, R.E., Wittenbrink, C.M., 1996. UFLOW: visualizing uncertainty in fluid flow. ACM, pp. 249-254. DOI: https://doi. org/10.1109/VISUAL.1996.568116

MacEachren, A.M., 1995. How Maps Work: Representation, Visualization and Design. The Guildford Press, New York, NY, USA.

MacEachren, A.M., 1992. Visualizing uncertain information. Cartographic Perspectives 13, 10-19. 
MacEachren, A.M., Brewer, C.A., Pickle, L.W., 1995. Mapping health statistics: Representing data reliability, in: Proceedings of the 17th International Cartographic Conference. Barcelona, Spain, pp. 311-319.

MacEachren, A.M., Brewer, C.A., Pickle, L.W., 1998. Visualizing georeferenced data: representing reliability of health statistics. Environment and Planning A 30, 1547-1561. DOI: https://doi.org/10.1068/a301547

MacEachren, A.M., Robinson, A., Hopper, S., Gardner, S., Murray, R., Gahegan, M., Hetzler, E., 2005. Visualizing geospatial information uncertainty: What we know and what we need to know. Cartography and Geographic Information Science 32, 139-160. DOI: https://doi.org/10.1559/1523040054738936

MacEachren, A.M., Roth, R.E., O’Brien, J., Li, B., Swingley, D., Gahegan, M., 2012. Visual semiotics \& uncertainty visualization: An empirical study. IEEE Transactions on Visualization and Computer Graphics 18, 2496-2505. DOI: https://doi.org/10.1109/TVCG.2012.279

McGranaghan, M., 1993. A cartographic view of spatial data quality. Cartographica: The International Journal for Geographic Information and Geovisualization 30, 8-19. DOI: https://doi.org/10.3138/310V-0067-7570-6566

McKenzie, G., Hegarty, M., Barrett, T., Goodchild, M., 2016. Assessing the effectiveness of different visualizations for judgments of positional uncertainty. International Journal of Geographical Information Science 30, 221239. DOI: https://doi.org/10.1080/13658816.2015.1082566

Monmonier, M., 1990. Strategies for the Interactive Exploration of Geographic Correlation. Proceedings of the 4th International Symposium on Spatial Data Handling, IGU:512-521., in: Brassel, K., Kishimoto, H. (Eds.), Proceedings of the 4th International Symposium on Spatial Data Handling. Department of Geography, University of Zurich, Switzerland, pp. 381-389.

Monmonier, M., Gluck, M., 1994. Focus groups for design improvement in dynamic cartography. Cartography and Geographic Information Systems 21, 37-47. DOI: https://doi.org/10.1559/152304094782563948

Mooney, P and Minghini, M. 2017. A Review of OpenStreetMap Data. In: Foody, G, See, L, Fritz, S, Mooney, P, Olteanu-Raimond, A-M, Fonte, C C and Antoniou, V. (eds.) Mapping and the Citizen Sensor. Pp. 37-59. London: Ubiquity Press. DOI: https://doi.org/10.5334/bbf.c.

Morrison, J., 1974. A theoretical framework for cartographic generalization with the emphasis on the process of symbolization. International Yearbook of Cartography 14, 115-127.

Mullen, W.F., Jackson, S.P., Croitoru, A., Crooks, A., Stefanidis, A., Agouris, P., 2015. Assessing the impact of demographic characteristics on spatial error in volunteered geographic information features. GeoJournal 80, 587-605. DOI: https://doi.org/10.1007/s10708-014-9564-8

Mullins, R.S., 2014. Interpretive uncertainty and the evaluation of symbols and a taxonomy of symbol evaluation methods and mobile evaluation tool. MSc Thesis. The Pennsylvania State University, The Graduate School, College of Earth and Mineral Sciences. 
Nedovic-Budic, Z., Budhathoki, N. R., 2010. Motives for VGI participants, in: Workshop "VGI for SDI?", Wageningen University and the Subcommission Geo-Information Infra-structure of the Netherlands Geodetic Commission, , Wageningen, Netherlands, 16 April. Available at: http://www.ncgeo. nl/phocadownload/Zorica_Nama_VGI_for_SDI.pdf [Last accessed 16 May 2017].

Olteanu-Raimond, A-M, Laakso, M, Antoniou, V, Fonte, C C, Fonseca, A, Grus, M, Harding, J, Kellenberger, T, Minghini, M, Skopeliti, A. 2017a. VGI in National Mapping Agencies: Experiences and Recommendations. In: Foody, G, See, L, Fritz, S, Mooney, P, Olteanu-Raimond, A-M, Fonte, C C and Antoniou, V. (eds.) Mapping and the Citizen Sensor. Pp. 299-326. London: Ubiquity Press. DOI: https://doi.org/10.5334/bbf.m.

Olteanu-Raimond, A.-M., Hart, G., Foody, G., Touya, G., Kellenberger, T., Demetriou, D., 2017b. The scale of VGI in map production: A perspective of European National Mapping Agencies. Transactions in GIS 21, 74-90. DOI: https://doi.org/10.1111/tgis.12189

OpenStreetMap Wiki, 2017. 3D, 17 February 2017. Available at http://wiki. openstreetmap.org/wiki/3D [Last accessed: 3 April 2017]

Pang, A.T., 2008. Visualizing uncertainty in natural hazards, in: Bostrom, A., French, P.S., Gottlieb, S. (Eds.), Risk Assessment, Modeling and Decision Support, Risk, Governance and Society. Springer Berlin Heidelberg, pp. 261-294.

Pang, A.T., 2001. Visualizing uncertainty in geo-spatial data. Computer Science and Telecommunications Board, Arlington, VA.

Pang, A.T., Wittenbrink, C.M., Lodha, S.K., 1997. Approaches to uncertainty visualization. The Visual Computer 13, 370-390. DOI: https://doi. org/10.1007/s003710050111

Parker, C.J., 2014. A framework of neogeography, in: The Fundamentals of Human Factors Design for Volunteered Geographic Information, SpringerBriefs in Geography. Springer International Publishing, Cham, pp. 11-22.

Retchless, D., 2012. Mapping Climate Change Uncertainty: Effects on Risk Perceptions and Decision Making. Poster. Presented at the AGU Fall Meeting, San Francisco, CA.

Roick, O., Loos, L., Zipf, A., 2012. Technical Framework for Visualizing Spatio-Temporal Quality Metrics of Volunteered Geographic Information, in: Proceedings of GEOINFORMATIK 2012-Mobility and Environment, Braunschweig, Germany, 28 - 30 March. Available at: http://koenigstuhl. geog.uni-heidelberg.de/publications/2012/Roick/Roick_OSMatrix_Geoinformatik2012.pdf [Last accessed 16 May 2017].

Roth, R.E., 2015. Visual variables, in: The International Encyclopedia of Geography: People, The Earth, Environment, and Technology. Wiley-Blackwell.

Schiewe, J., 2013. Improving collective intelligence and exploration in a VGI like context through communication of uncertainty information. Presented at the GeoVIz, Hamburg, Germany. 
Schweizer, D.M., Goodchild, M.F., 1992. Data quality and choropleth maps: An experiment with the use of color, in: Proceedings of GIS/LIS'92. Presented at the GIS/LIS'92, ACSM and ASPRS, San Jose, CA, USA, pp. 686-699.

See, L, Estima, J, Pőd.r, A, Arsanjani, J J, Bayas, J-C L and Vatseva, R. 2017. Sources of VGI for Mapping. In: Foody, G, See, L, Fritz, S, Mooney, P, Olteanu-Raimond, A-M, Fonte, C C and Antoniou, V. (eds.) Mapping and the Citizen Sensor. Pp. 13-35. London: Ubiquity Press. DOI: https://doi. org/10.5334/bbf.b.

Senaratne, H., Gerharz, L., Pebesma, E., Schwering, A., 2012. Usability of spatio-temporal uncertainty visualisation methods, in: Gensel, J., Josselin, D., Vandenbroucke, D. (Eds.), Bridging the Geographic Information Sciences. Springer Berlin Heidelberg, Berlin, Heidelberg, pp. 3-23.

Senaratne, H., Mobasheri, A., Ali, A.L., Capineri, C., Haklay, M. (Muki), 2016. A review of volunteered geographic information quality assessment methods. International Journal of Geographical Information Science 1-29. DOI: https://doi.org/10.1080/13658816.2016.1189556

Sester, M., Jokar Arsanjani, J., Klammer, R., Burghardt, D., Haunert, J.-H., 2014. Integrating and generalising Volunteered Geographic Information, in: Burghardt, D., Duchêne, C., Mackaness, W. (Eds.), Abstracting Geographic Information in a Data Rich World. Springer International Publishing, Cham, pp. 119-155.

Slocum, T.A., McMaster, R.B., Kessler, F.C., Howard, H.H., 2003. Thematic Cartography and Geovisualization. Pearson Prentice Hall, Upper Saddle River NJ.

Trame, J., Keßler, C., 2011. Exploring the lineage of Volunteered Geographic Information with heat maps in: Proceedings of GeoVIz 2011, Hamburg, Germany, 10-11 March. Available at: http://www.geomatik-hamburg.de/ geoviz11/abstracts/28_TrameKessler_Abstract_GeoViz2011.pdf [Last accessed 16 May 2017].

Tulloch, D.L., 2008. Is VGI participation? From vernal pools to video games. GeoJournal 72, 161-171. DOI: https://doi.org/10.1007/s10708-008-9185-1

Van der Wel, F.J., Van der Gaag, L.C., Gorte, B.G., 1998. Visual exploration of uncertainty in remote-sensing classification. Computers \& Geosciences 24, 335-343. DOI: https://doi.org/10.1016/S0098-3004(97)00120-9

van Exel, M., 2011a. A new OpenStreetmap visualization: Version contour lines. Oegeo Martijn van Exel and his OpenStreetMap adventures [blog] 20 June 2011. Available at: https://oegeo.wordpress.com/2011/06/20/a-new-openstreetmap-visualization-version-contour-lines/ [Last accessed 16 May 2017] van Exel, M., 2011b. A new OpenStreetmap visualization: Taking the temperature of local OpenStreetMap communities. Oegeo Martijn van Exel and his OpenStreetMap adventures [blog] 19 September 2011. Available at: https:// oegeo.wordpress.com/2011/09/19/taking-the-temperature-of-local-openstreetmap-communities/ [Last accessed 16 May 2017] 
van Exel, M., Dias, E., Fruijtier, S., 2010. The impact of crowdsourcing on spatial data quality indicators, in: Wallgrün, J.O., Lautenschütz, A.K. (eds.), Proceedings of the GIScience 2010 Doctoral Colloquium, Zurich, Switzerland, 14-17 September 2010. Available at: http://www.giscience2010.org/ pdfs/paper_213.pdf [Last accessed 16 May 2017]

Vandecasteele, A., Devillers, R., 2015. Improving volunteered geographic information quality using a tag recommender system: The case of OpenStreetMap, in: Jokar Arsanjani, J., Zipf, A., Mooney, P., Helbich, M. (Eds.), OpenStreetMap in GIScience, Lecture Notes in Geoinformation and Cartography. Springer International Publishing, Cham, Switzerland, pp. 59-80.

Vullings, L.A.E., Bulens, J.D., Rip, F.I., Boss, M., Meijer, M., Hazeu, G., Storm, M., 2015. Spatial data quality: What do you mean? ?, in: Proceedings of 18th AGILE International Conference on Geographic Information Science, Lisbon, Portugal, 9-12 June 2015, pp. 9-12. Available at: https://agile-online. org/conference_paper/cds/agile_2015/shortpapers/87/87_Paper_in_PDF. pdf [Last accessed 16 May 2017]

Wilkinson, L., 2005. The Grammar of Graphics (Statistics and Computing). Springer-Verlag, New York.

Wittenbrink, C.M., Pang, A.T., Lodha, S.K., 1996. Glyphs for visualizing uncertainty in vector fields. IEEE Transactions on Visualization and Computer Graphics 2, 266-279. DOI: https://doi.org/10.1109/2945.537309

Zielstra, D., Zipf, A., 2010. A comparative study of proprietary geodata and volunteered geographic information for Germany. Presented at the 13th AGILE International Conference on Geographic Information Science 2010, Guimarães, Portugal, pp. 1-15.

Zuk, T., Carpendale, S., 2006. Theoretical analysis of uncertainty visualizations, in: Proceedings of the International Society for Optics and Photonics (SPIE) - Visualization and Data Analysis, 15-19 January 2006, San Jose, California, USA, p. 606007. DOI: https://doi.org/10.1117/12.643631 